\title{
Propriedades de Barreira e Solubilidade de Filmes de Amido de Ervilha Associado com Goma Xantana e Glicerol
}

\author{
Manoel D. da Matta Jr., Silene B. S. Sarmento \\ Departamento de Agroindústria, Alimentos e Nutrição, ESALQ/USP \\ Claire I. G. L. Sarantópoulos \\ Centro de Tecnologia de Embalagem, ITAL \\ Silvio S. Zocchi \\ Departamento de Ciências Exatas, ESALQ/USP
}

\begin{abstract}
Resumo: O objetivo do trabalho foi avaliar as propriedades de barreira e a solubilidade de biofilmes obtidos a partir de amido de ervilha de alto teor de amilose em associação à goma xantana e glicerol. Soluções filmogênicas (SF) com diferentes teores de amido de ervilha (3, 4 e $5 \%$ ), goma xantana $(0,0,05$ e $0,1 \%)$ e glicerol (proporção glicerol-amido de 1:5 P/P) foram estudadas. As SF foram obtidas por ebulição (5 minutos), seguida de autoclavagem por 1 hora a $120^{\circ} \mathrm{C}$ e os filmes foram preparados por casting. O aumento da concentração de amido e de glicerol na composição causou aumento da espessura e da solubilidade dos filmes em água. O plastificante gerou ainda elevação dos coeficientes de permeabilidade ao vapor d'água e ao oxigênio. O aumento da concentração da goma xantana não interferiu nas propriedades estudadas. Os biofilmes obtidos a partir de amido de ervilha verde, associado ou não à goma xantana e glicerol, se comparados com filmes de amido de ervilha amarelas e outras fontes de amido, apresentaram boa barreira ao oxigênio e ao vapor d'água e baixa solubilidade em água.
\end{abstract}

Palavras-chave: Biopolímeros, propriedades de barreira, amido de ervilha, goma xantana.

\section{Barrier Properties of Films of Pea Starch associated with Xanthan Gum and Glycerol}

\begin{abstract}
The aim of this work was to evaluate the barrier properties and solubility of biofilms made from wrinkled pea starch with high amylose content in association with xanthan gum and glycerol. Filmogenic solution (FS) with different levels of pea starch (3, 4 and 5\%), xanthan gum $(0,0.05$ and $0.1 \%)$ and glycerol (glycerol-starch 1:5 W/W) were tested. FS was obtained by boiling (5 minutes), autoclaving for 1 hour at $120{ }^{\circ} \mathrm{C}$ and the films were prepared by casting. The increased concentration of starch and glycerol in the composition caused increases in thickness of the films and in their solubility in water. The plasticizer also generated higher coefficients of water vapor and oxygen permeabilities to water vapor and to oxygen. The increasing concentration of xanthan gum did not interfere in the properties studied. Biofilms produced with wrinkled pea starch, with or without xanthan gum and glycerol, showed better barrier to oxygen and water vapor and low solubility in water, in comparison with films of yellow pea starch and other starch sources.
\end{abstract}

Keywords: Biofilm, pea starch, hydrocolloid, plasticizer, barrier properties.

\section{Introdução}

Polímeros provenientes de fontes naturais renováveis têm sido foco de interesse para o desenvolvimento de novas tecnologias que visam a preservação ambiental e a busca de potenciais alternativas de substituição de plásticos convencionais oriundos do petróleo ${ }^{[1]}$. Neste contexto, o amido tem sido considerado um polímero com elevado potencial para produzir biofilmes, por ser de baixo custo, alta disponibilidade, de fonte renovável e biodegradável. Filmes obtidos de amidos, em sua maioria, apresentam boas características de barreira ao oxigênio, entretanto, uma série de limitações é observada com relação às suas características hidrofílicas e permeabilidade ao vapor d'água.

O amido de ervilha apresenta teores elevados de amilose, podendo chegar a $76 \%$ em algumas variedades ${ }^{[2]}$, sendo uma boa fonte para obtenção de filmes flexíveis. Na literatura constam estudos sobre filmes deste amido, mas apenas os de fontes comerciais de ervilhas amarelas, com teor de amilose entre 30-40\%, os quais apresentaram boas propriedades mecânicas e de barreira a gás, contudo baixa permeabilidade ao vapor d'água ${ }^{[2-5]}$.
Associações amidos/hidrocolóides também têm sido estudadas visando novas formulações com o intuito de melhorar as características dos filmes. Os hidrocolóides podem interferir na gelatinização e retrogradação dos amidos ${ }^{[6-9]}$, propriedades que podem afetar as características dos filmes. Dentre as explicações propostas para tal estão a associação destes com o amido intumescido ou com as cadeias de amilose lixiviadas na pasta e a competição com o amido pela água. Estas associações são altamente dependentes da estrutura do hidrocolóide ${ }^{[10]}$. Exemplo de hidrocolóide associado com amido para obtenção de filmes está o estudo da interação xantana (0 a $0,1 \%$ p/p) e amido de mandioca (3-5\%), onde o acréscimo da xantana não teve impacto significativo sobre a cinética de absorção de água dos filmes, quando comparados ao controle (5\% de amido de mandioca) ${ }^{[11]}$. Foi também estudada a associação amido de ervilha hidroxipropilada e $\kappa$-carragena, sendo observado aumento da viscosidade da pasta a quente, melhoria nas propriedades de geleificação, secagem e formação do filme, sem alterações nas suas propriedades ${ }^{[12]}$.

Autor para correspondência: Silene B. S. Sarmento, Departamento de Agroindústria, Alimentos e Nutrição, Escola Superior de Agricultura Luiz de Queiroz, Caixa Postal 9, CEP: 13418-900, Piracicaba, SP, Brasil. E-mail: sbssarme@usp.br 
As interações entre as moléculas de amilose e de amilopectina contribuem para a formação do filme, mas quando muito intensas, tornam os filmes quebradiços e rígidos. Assim, a presença dos plastificantes nestes filmes ajudaria a interromper a formação de dupla hélice da amilose com fragmentos da amilopectina, reduzindo assim a interação entre elas, conferindo maior flexibilidade. $\mathrm{O}$ glicerol é considerado um plastificante dos mais efetivos em termos de propriedades termomecânicas ${ }^{[3]}$. O plastificante reduz o número de pontes de hidrogênio entre as cadeias dos polímeros e interfere no espaço molecular ${ }^{[13]}$. A barreira dos filmes de amido ao vapor d'água, entretanto, é reduzida com o plastificante ${ }^{[14]}$.

O objetivo do estudo foi avaliar as propriedades de barreira dos filmes obtidos a partir de amido de ervilha de alto teor de amilose associado à goma xantana e ao glicerol.

\section{Experimental}

\section{Material}

O amido foi extraído de ervilha (Pisum sativum L.) verde, do tipo rugosa, da cultivar Utrillo. As ervilhas frescas foram adquiridas no CEASA-SP. Seu teor de amilose é de $61 \%{ }^{[15]}$. A goma xantana utilizada foi cedida pela CPKelco, marca Keltrol®RD.

\section{Métodos}

Os filmes foram preparados por casting, que consiste na desidratação de uma solução filmogênica (SF) colocada em placas Plexiglass ( $15 \mathrm{~cm}$ de diâmetro). As SF foram obtidas por aquecimento (temperatura de ebulição) por 5 minutos e, posteriomente, autoclavadas por 1 hora. a $121{ }^{\circ} \mathrm{C}$ e 1 atm. As amostras foram desidratadas em estufa a $37^{\circ} \mathrm{C}$ por 3 horas e a conclusão da secagem ocorreu em temperatura ambiente por 2 horas.

$\mathrm{O}$ aspecto dos filmes foi observado em microscópio eletrônico de varredura (MEV), marca ZEISS DSM 940 A, amperagem de $80 \mathrm{~mA}$ e voltagem de $5 \mathrm{Kv}$. A montagem das amostras foi feita em suportes (stubs) com fita adesiva dupla face, onde os filmes fixados e cobertos com camada de ouro, em metalizador Balzers Med 010 por 3 minutos. Os filmes foram congelados em nitrogênio líquido, fragmentados com bisturi e fixados na fita adesiva dupla face no sentido transversal (espessura).

A espessura dos filmes foi determinada com micrômetro digital Mitutoyo, mod. MDC 25 SB e calculada como média aritmética de 12 medidas aleatórias.

A solubilidade dos filmes em água foi avaliada segundo a metodologia de Gontard et al. ${ }^{[16]}$ modificada. Filmes condicionados a $51 \%$ UR por 72 horas em dessecador contendo solução super saturada de cloreto de cálcio foram cortados em círculos $(2 \mathrm{~cm}$ diâmetro), secos em estufa $\left(70{ }^{\circ} \mathrm{C}\right)$ até peso constante e colocados em béquer contendo $50 \mathrm{~mL}$ de água destilada e fechado com folha de alumínio. $\mathrm{O}$ material foi mantido a $25^{\circ} \mathrm{C}$ por 24 horas, em banho marca Marconi, MA 095 com agitação (100 rpm) e posteriormente, desidratados a $70{ }^{\circ} \mathrm{C}$ por 24 horas.

A taxa de permeabilidade ao vapor d'água (TPVA) foi determinada a $23{ }^{\circ} \mathrm{C}$ e $75 \%$ UR por método gravimétrico, segundo procedimento ASTM E 96/E 96 ${ }^{[17]}$. O ganho de peso de cloreto anidro dentro de cápsulas de alumínio, fechadas com os filmes, foi quantificado em balança analítica Mettler, mod. AT 400, com resolução de $10^{-4} \mathrm{~g}$. A taxa de permeabilidade ao oxigênio $\left(\mathrm{TPO}_{2}\right)$ foi determinada por método coulométrico segundo a norma ASTM F $1927^{[18]}$, em equipamento OX-TRAN, da MOCON, mod. 2/20, operando com oxigênio puro como gás permeante a $23{ }^{\circ} \mathrm{C}$ e $75 \%$ UR. A área efetiva de permeação de cada corpo de prova foi de $50 \mathrm{~cm}^{2}$ para ambos os ensaios de permeabilidade. Foi também feita a conversão das taxas de permeabilidade em coeficientes de permeabilidade, multiplicando-se a taxa pela espessura média de cada corpo-de-prova e dividindo-se pelo gradiente de pressão parcial do permeante entre as faces do filme.

$\mathrm{O}$ delineamento fatorial completo $2^{3}$ foi adotado para estudar a influência das variáveis explanatórias, concentrações de amido $\left(x_{1}\right)$, concentração de goma $\left(x_{2}\right)$ e concentração de glicerol $\left(x_{3}\right)$ sobre as propriedades (variáveis resposta $y$ ) dos filmes. O delineamento completo (Tabela 1) consiste em 13 pontos experimentais, incluindo cinco repetições do ponto central $\left(x_{1}=0, x_{2}=0\right.$ e $\left.x_{3}=0\right)$, incluídos de forma a se estimar o erro puro e testar a falta de ajuste dos modelos propostos. $\mathrm{O}$ ajuste do modelo e a simplificação do mesmo foram realizados pelo stepwise e procedimento REG do pacote estatístico SAS, versão 9.0 (STATISTICAL ANALYSIS SYSTEM, 1990). Os gráficos dos modelos matemáticos significativos foram obtidos pelo sistema de álgebra computacional da Maplesoft, versão 9.5 (Maplesoft 2004).

\section{Resultados e Discussão}

Dos 9 tratamentos propostos, o T5 não gerou filmes aptos para análise. Tais filmes, ao final do processo de secagem, apresentavam bordas que se enrolavam e de difícil manuseio (muito rígidos e quebradiços). O elevado teor de amido (5\%) com alto teor de amilose, sem a adição de goma ou glicerol impediram a formação de filme viável.

As fotomicrografias da superfície superior dos filmes (Figuras 1a e b) de todos os tratamentos mostraram uma massa extensa e amorfa, com a presença de relevos ou depressões arredondadas. Estes relevos podem decorrer da presença de grânulos não totalmente gelatinizados e não fragmentados em meio à massa. Estes grânulos de amido mais na superfície são observados em simples relevo ou com sulco ao derredor. Estes últimos podem ter sido formados em decorrência da secagem. Os formatos dos grânulos de amido que aparecem nas fotos são compatíveis com aqueles citados na literatura para ervilhas, ou seja, arredondados, ovalados e formas irregulares compostas de mais de um grânulo, dispostos em forma de círculo ${ }^{[19-21]}$.

As macromoléculas do amido de ervilha requerem temperaturas elevadas de mais de $100{ }^{\circ} \mathrm{C}$ para sua completa solubilização ${ }^{[22]}$, mesmo com pressão extra e um tempo mais longo. Além disso, os grânulos de amido acrescidos de goma podem também ter a capacidade de inchamento reduzida por estarem sujeitos ao envolvimento pela xantana ${ }^{[10]}$.

Tabela 1. Variáveis explicativas* codificadas e seus valores reais (\% entre parênteses).

\begin{tabular}{rccc}
\hline & $x \mathbf{1}$ & $x \mathbf{2}$ & $x \mathbf{3}$ \\
\hline 1 & $-1(3)$ & $-1(0)$ & $-1(0)$ \\
2 & $-1(3)$ & $-1(0)$ & $1(20)$ \\
3 & $-1(3)$ & $1(0,10)$ & $-1(0)$ \\
4 & $-1(3)$ & $1(0,10)$ & $1(20)$ \\
5 & $1(5)$ & $-1(0)$ & $-1(0)$ \\
6 & $1(5)$ & $-1(0)$ & $1(20)$ \\
7 & $1(5)$ & $1(0,10)$ & $-1(0)$ \\
8 & $1(5)$ & $1(0,10)$ & $1(20)$ \\
9 & $0(4)$ & $0(0,05)$ & $0(10)$ \\
10 & $0(4)$ & $0(0,05)$ & $0(10)$ \\
11 & $0(4)$ & $0(0,05)$ & $0(10)$ \\
12 & $0(4)$ & $0(0,05)$ & $0(10)$ \\
13 & $0(4)$ & $0(0,05)$ & $0(10)$ \\
\hline
\end{tabular}

$* \mathrm{x}_{1}=$ amido; $\mathrm{x}_{2}=$ goma e $\mathrm{x}_{3}=$ glicerol. 


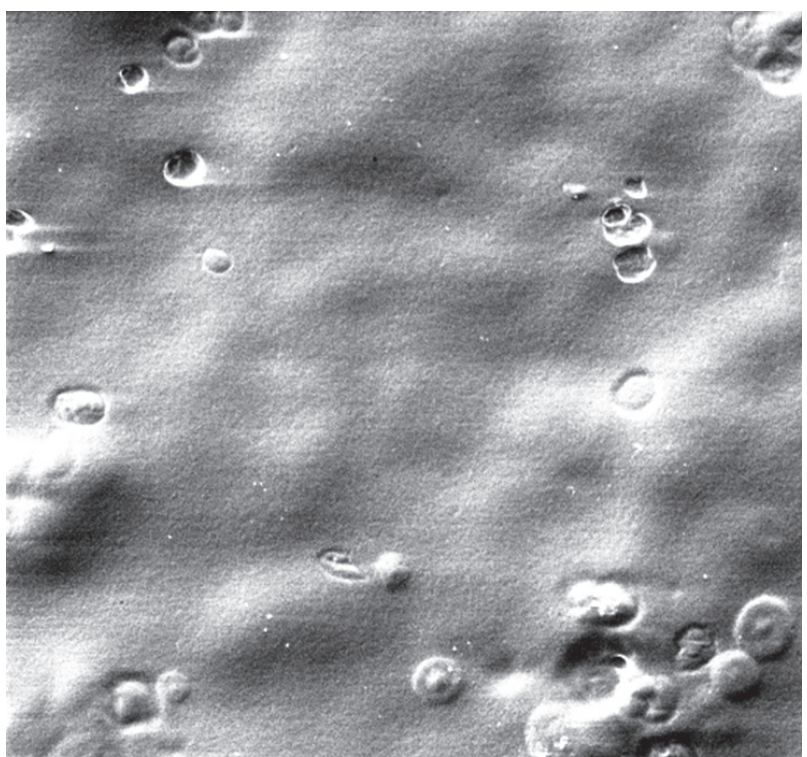

(a)

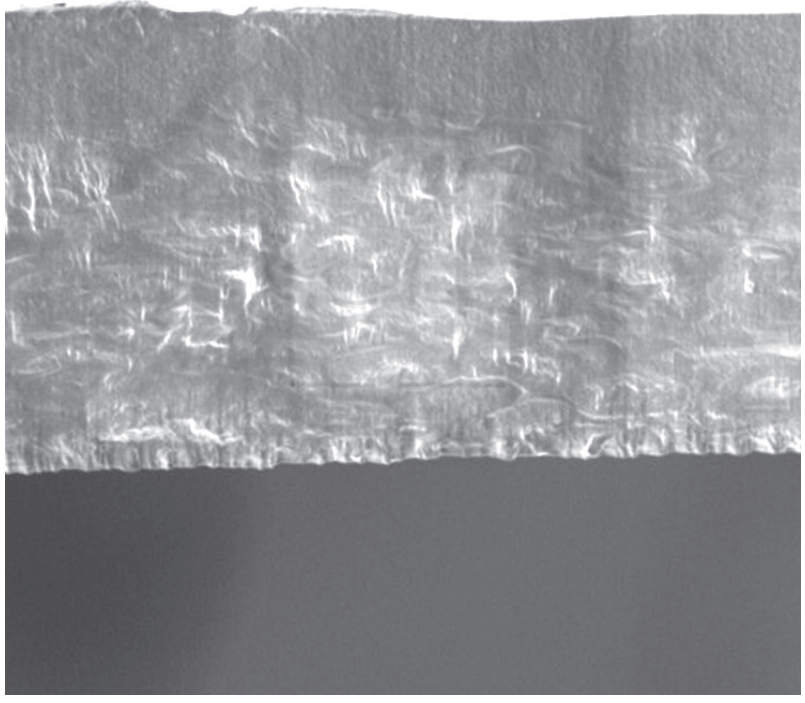

(c)

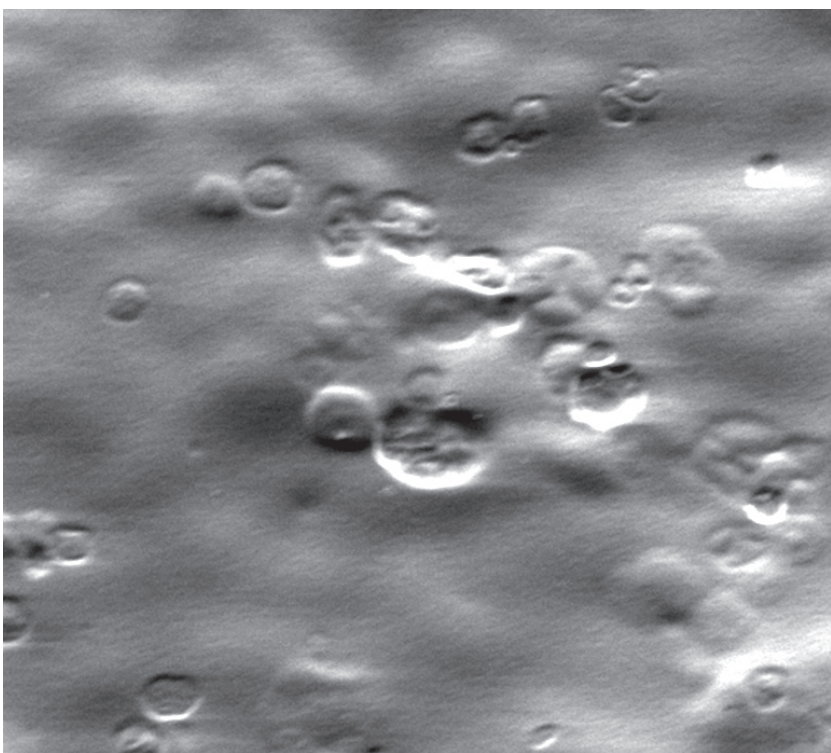

(b)

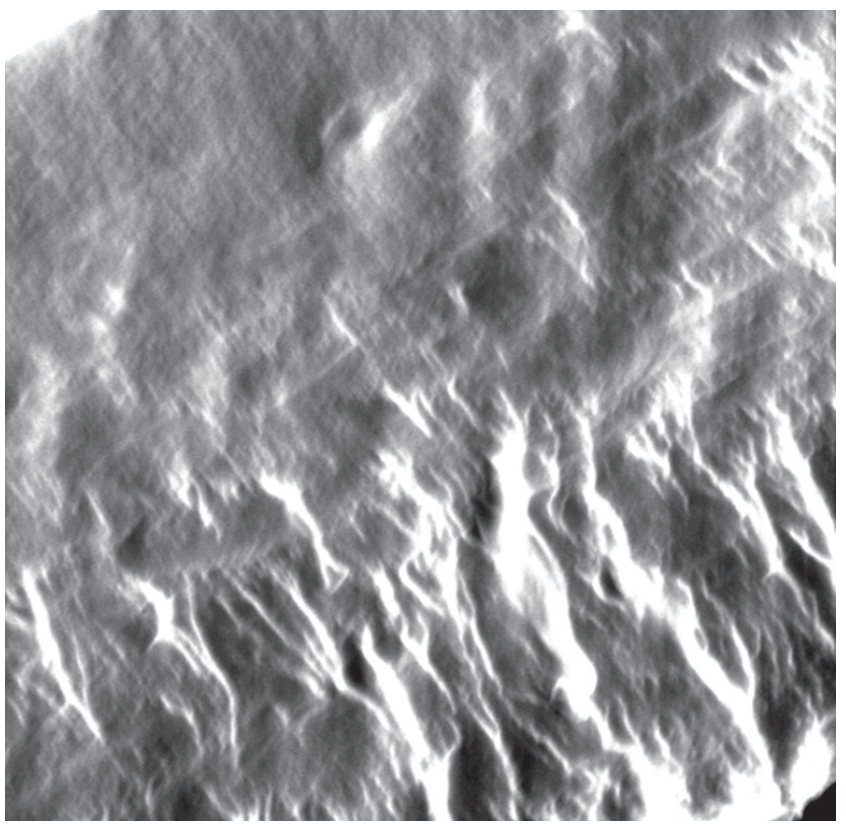

(d)

Figura 1. Fotomicrografias da superfície e seção transversal dos filmes de amido de ervilha. a) Superfície do filme T3 (3\% amido e 0,1\% goma); b) superfície do filme T9 (4\% amido, $20 \%$ glicerol e 0,05\% goma); c) seção transversal do filme T1 (3\% amido); d) seção transversal do filme T9 (4\% amido, $20 \%$ glicerol e $0,05 \%$ goma) em aumento maior que (c).

A superfície dos filmes, vista ao microscópio, apresenta-se como um arranjo desordenado de grânulos e seus fragmentos. Enquanto a solução filmogênica está sendo desidratada para formar os filmes, devido à força motriz da evaporação da água, um grande número de grânulos de amido expandidos e suas reminiscências é agregado ao acaso e compactado para compor os filmes ${ }^{[23]}$. Por outro lado, em filmes de outras fontes de amido também foram detectados grânulos e seus fragmentos, como em Leyva et al. ${ }^{[24]}$ para amido de trigo e por Zhang e $\mathrm{Han}^{[22]}$ em filmes de amido de ervilha amarela tipo Field, cv Miranda.

O aspecto da seção transversal dos filmes foi semelhante para todos os tratamentos (Figuras 1c e d), tendo uma fase (camada superior) mais homogênea e outra menos homogênea (camada inferior). Esta divisão de fases provavelmente decorre da velocidade de deposição ou de secagem dos componentes da solução filmogênica na placa de Plexiglass. Não foi observada diferença entre os filmes com e sem plastificante ou com e sem goma.

A análise de variância das propriedades dos filmes em função de sua composição é apresentada na Tabela 2. Para os coeficientes de permeabilidade ao vapor d'água e ao oxigênio não foi possível ajustar modelo que correlacionasse as propriedades com as formulações estudadas.

Os modelos que se apresentaram de acordo com os dados experimentais foram utilizados para estudar o efeito das condições de formação do filme nas propriedades dos mesmos. $\mathrm{O}$ teor de amido 
na solução filmogênica influenciou as propriedades dos filmes de maneiras distintas. Os coeficientes dos modelos de regressão para os parâmetros espessura e solubilidade foram significativos em nível de $1 \%$. A concentração do glicerol influenciou a solubilidade dos filmes, para a qual o coeficiente do modelo de regressão foi significativo em nível de $1 \%$. A influência da goma sobre o coeficiente de permeabilidade ao vapor d'água e ao oxigênio dos filmes mostrou falta de ajuste estatisticamente significativa dos modelos, porém, evidenciou a necessidade de ensaios adicionais (pontos axiais extras) para o melhor ajuste dos modelos polinomiais de $2^{\mathrm{a}}$ ordem completos.

A espessura dos filmes variou de $0,055 \mathrm{~mm}$ para o tratamento T1 (contendo apenas amido 3\%) até $0,098 \mathrm{~mm}$ para o T6 (5\% de amido e $20 \%$ de glicerol), sendo que o filme do tratamento no ponto central (T9) apresentou $0,073 \mathrm{~mm}$. A espessura foi maior quanto mais elevado o teor de amido e de glicerol na solução filmogênica (Figura 2). Pelo modelo de regressão verifica-se que o acréscimo de amido resultou em aumento de $0,011 \mathrm{~mm}$ no valor da espessura, enquanto que o aumento do teor de glicerol implicou em aumento de $0,007 \mathrm{~mm}$.

Durante a secagem das soluções filmogênicas a água evapora permitindo uma maior concentração de amido por área formadora de rede. A quantidade de goma utilizada, por seus teores, não contribuiu significativamente com o teor de sólidos, entretanto, o glicerol, além de contribuir com sólidos, altera a estrutura formada. O glicerol atua interrompendo a formação de dupla hélice da amilose com fragmentos da amilopectina, reduzindo a interação entre as moléculas de amilose e amilopectina. A redução das associações diretas diminui a retração do gel e aumenta a espessura dos filmes ${ }^{[3]}$.

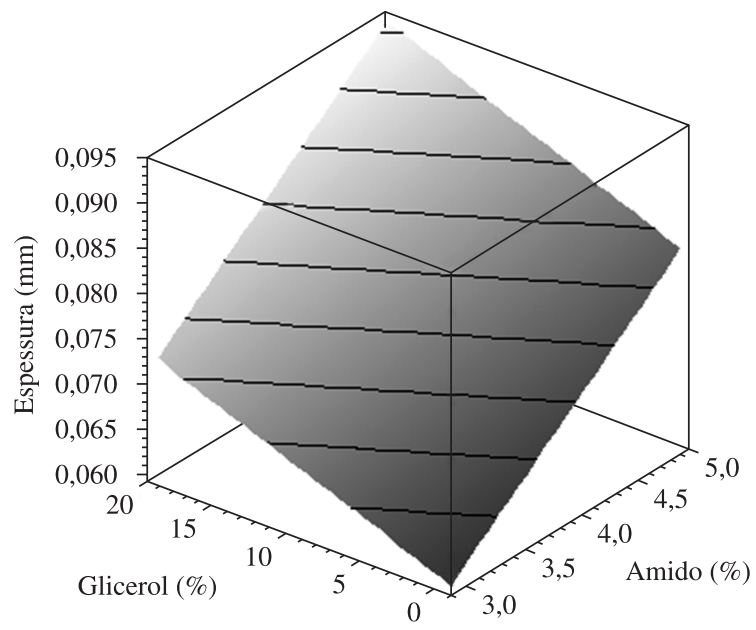

Figura 2. Superfície de resposta para o efeito da concentração do glicerol e do amido na espessura dos filmes de amido de ervilha.
Para Zhang e $\operatorname{Han}^{[22]}$ a espessura, muito mais do que uma simples relação de depósito de sólidos, é uma resposta à conformação molecular e geometria das interações entre a matriz do filme e o agente plastificante utilizado.

Tendências opostas foram encontradas na literatura. Leyva ${ }^{[24]}$ e Laohakunjit e Noomhorm ${ }^{[25]}$ observaram que o glicerol elevou a espessura de filmes de amido de trigo e de arroz, respectivamente. Já outro estudo ${ }^{[26]}$ evidenciou efeito oposto em filmes de amido de milho.

A solubilidade dos filmes em água é uma importante propriedade, podendo atuar como proteção para alimentos em que a atividade de água é alta, quando o alimento tem contato com a água durante a cocção ${ }^{[16]}$ ou mesmo quando os filmes são ingeridos (comestíveis).

Todos os filmes de ervilha estudados, depois de ficarem imersos em água por 24 horas sob agitação, apresentaram-se inteiros e aparentemente íntegros quanto à forma, bem flexíveis e dobráveis ao manuseio. No aspecto visual, entretanto, os filmes apresentaramse opacos.

As maiores solubilidades foram as do tratamento T6 (5\% amido e $20 \%$ glicerol) e T8 (5\% amido, 0,1\% goma e $20 \%$ glicerol), que foram de 18,39 e 18,19\%, respectivamente. Esses filmes apresentaram-se como os mais espessos, tendo em comum a presença do glicerol e de amido nas concentrações máximas. $\mathrm{O}$ de menor solubilidade $(3,14 \%$ ) foi o T3 (3\% amido e $0,1 \%$ goma). A solubilidade da formulação no ponto central (T9) foi de $11,75 \%$.

A resistência à umidade dos filmes de amido de ervilha da cultivar Utrillo foi superior à verificada por Wang et al. ${ }^{[27]}$ para filme de amido de batata (3 e 50\% glicerol), cuja solubilidade foi de $31,8 \%$. A influência da concentração de amido na solubilidade de biofilmes, contudo não foi verificada por Wang et al. ${ }^{[27]}$. Mehyar e $\mathrm{Han}^{[5]}$ constataram que as interações da rede formada pelo amido de ervilha geraram maior resistência à água que o filme de amido de arroz. Estes últimos autores sugeriram que no caso do amido de ervilha ( $10 \%$ a mais de amilose) o aumento da força inter-molecular destes polissacarídeos poderia ter sido causado pela maior interação entre as moléculas de amilose, o que, por hipótese, é o principal mecanismo de formação de filmes de amido.

Dentre os aumentos de solubilidade observados devido ao incremento de amido e de glicerol na formulação, o deste último foi mais intenso (Figura 3).

A adição de plastificante, em particular o glicerol, tem uma grande influência sobre a solubilidade de filmes de amido, devido ao seu caráter hidrofílico. O glicerol interage com a matriz do filme aumentando o espaço livre entre as cadeias, facilitando a entrada da água no filme e, conseqüentemente, aumentado a solubilidade ${ }^{[5,22,24,25,28]}$.

A solubilidade dos tratamentos T3 (sem glicerol) e T4 $(20 \%$ glicerol), ambos com a mesma concentração de amido e de goma, aumentou 4 vezes em função da adição do glicerol. O mesmo efeito

Tabela 2. Estimativas dos coeficientes dos modelos polinomiais de regressão selecionados utilizando-se o método "stepwise" e respectivos coeficientes de determinação $\left(\mathrm{R}^{2}\right)$, valor-p do teste de significância do modelo, coeficiente de variação $(\mathrm{CV})$ e valor-p do teste para falta de ajuste do modelo.

\begin{tabular}{|c|c|c|c|c|c|c|c|c|c|c|c|c|c|c|c|c|c|}
\hline \multirow{2}{*}{$\begin{array}{c}\text { Variável resposta } \\
(\mathbf{y})\end{array}$} & \multicolumn{13}{|c|}{ Coeficientes do modelo de regressão } & \multirow[t]{2}{*}{$\mathbf{R}^{2}$} & \multirow{2}{*}{$\begin{array}{l}\text { Modelo } \\
\text { (p) }\end{array}$} & \multirow{2}{*}{$\begin{array}{l}\text { CV } \\
(\%)\end{array}$} & \multirow{2}{*}{$\begin{array}{c}\text { Falta de } \\
\text { ajuste } \\
\text { (p) }\end{array}$} \\
\hline & $\beta_{0}$ & $\beta_{1}$ & & $\beta_{2}$ & & $\beta_{3}$ & & $\beta_{12}$ & & $\beta_{13}$ & & $\beta_{23}$ & & & & & \\
\hline Espessura & 0,077 & 0,011 & $* * *$ & & & 0,007 & $*$ & & & & & & & 0,66 & 0,0074 & 11,1 & 0,3765 \\
\hline Taxa perm. vapor água & 471,876 & $-145,589$ & $* *$ & & & & & & & & & & & 0,34 & 0,0475 & 35,0 & 0,1260 \\
\hline Coef. perm. água & 14,051 & $-2,920$ & & 3,639 & * & $-0,109$ & & 3,074 & & 3,337 & $*$ & $-3,468$ & $*$ & 0,71 & 0,2321 & 22,7 & 0,0050 \\
\hline Taxa perm. $\mathrm{O}_{2}$ & 8,431 & $-2,673$ & $*$ & 1,347 & & 4,783 & $* * *$ & 2,771 & $*$ & 1,580 & & $-2,163$ & & 0,79 & 0,1121 & 25,7 & 0,0112 \\
\hline Coef. perm. $\mathrm{O}_{2}$ & 6,134 & 0,526 & & 0,423 & & 3,117 & $* * *$ & 1,434 & & 1,296 & & & & 0,78 & 0,0520 & 28,3 & 0,0060 \\
\hline Solubilidade & 11,172 & 2,074 & $* * *$ & & & 4,649 & $* * *$ & & & & & & & 0,90 & 0,0001 & 13,9 & 0,1383 \\
\hline
\end{tabular}

$*, * * \mathrm{e}^{* * *}=$ significativo considerando-se os níveis de significância 10,5 e $1 \%$, respectivamente. 
Tabela 3. Valores médios dos coeficientes de permeabilidade ao vapor d’água e ao oxigênio $\left(23{ }^{\circ} \mathrm{C}\right.$ e $75 \%$ UR) dos biofilmes de amido de ervilha.

\begin{tabular}{|c|c|c|c|c|c|c|c|c|c|}
\hline \multirow{2}{*}{$\begin{array}{l}\text { Coeficiente de } \\
\text { permeabilidade }\end{array}$} & \multicolumn{9}{|c|}{ Tratamentos } \\
\hline & T1 & $\mathbf{T 2}$ & T3 & T4 & T5 & T6 & T7 & T8 & T9 \\
\hline $\begin{array}{c}\text { Ao vapor d'água } \\
\left(\mathrm{g} \cdot \mu \mathrm{m} \cdot \mathrm{m}^{-2} \cdot \mathrm{dia}^{-1} \cdot \mathrm{kPa}^{-1}\right)\end{array}$ & $19,12 \cdot 10^{3}$ & $16,43 \cdot 10^{3}$ & $24,45 \cdot 10^{3}$ & $13,36 \cdot 10^{3}$ & - & $13,86 \cdot 10^{3}$ & $20,82 \cdot 10^{3}$ & $17,60 \cdot 10^{3}$ & $9,44 \cdot 10^{3}$ \\
\hline $\begin{array}{c}\text { Ao oxigênio } \\
\left(\mathrm{mL}(\mathrm{CNTP}) \mu \mathrm{m} \cdot \mathrm{m}^{-2} \cdot \mathrm{dia}^{-1} \cdot \mathrm{kPa}^{-1}\right)\end{array}$ & 4,65 & 10,19 & 4,53 & 6,27 & - & 10,81 & 5,70 & 12,93 & 3,81 \\
\hline
\end{tabular}

O Tratamento T9 representa aqui a média de todos os pontos centrais (T9 a T13).

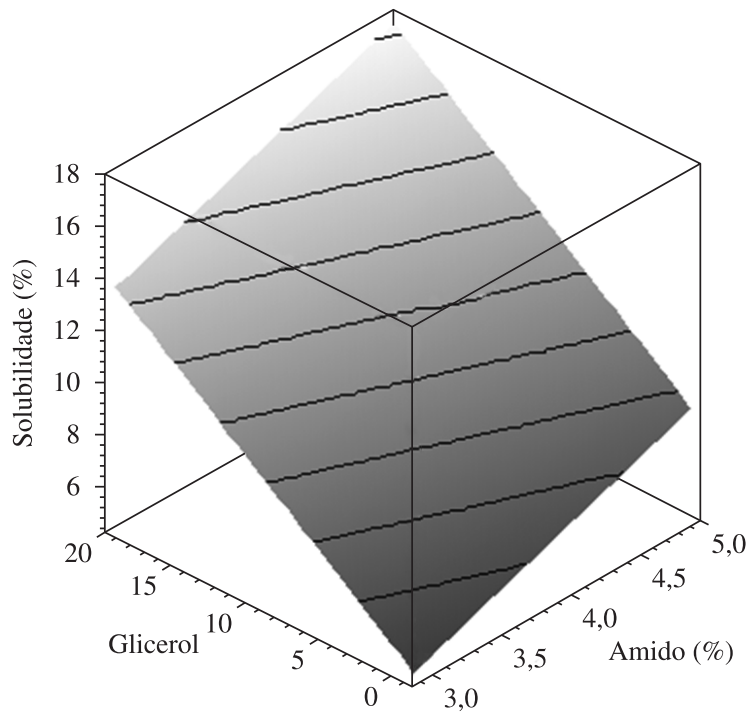

Figura 3. Superfície de resposta do efeito da concentração do glicerol e do amido na solubilidade de filmes de amido de ervilha.

do glicerol foi verificado em filmes de amido de arroz ${ }^{[25]}$, $\operatorname{trigo}^{[24]} \mathrm{e}$ ervilha $^{[5]}$

As propriedades de barreira dos filmes dependem da temperatura e da umidade relativa do ambiente, das características do biopolímero e da interação entre o polímero e o permeante, associada à polaridade. Dentre as características mais importantes do filme relacionadas à permeação estão a espessura, a estrutura química do biopolímero, sua morfologia (especialmente a cristalinidade), a energia de coesão e o espaço-livre entre as macromoléculas. Estas características advêm da formulação e do processo de obtenção ${ }^{[29-31]}$.

Os coeficientes médios de permeabilidade ao vapor d'água são apresentados na Tabela 3. Não houve ajuste do modelo matemático para explicar o efeito dos componentes da formulação dos filmes na variação desta propriedade do material.

O menor valor de coeficiente de permeabilidade ao vapor d'água foi verificado para o ponto central do experimento (T9), cuja permeabilidade foi de $9 \cdot 10^{3} \mathrm{~g} \cdot \mu \mathrm{m} \cdot \mathrm{m}^{-2} \cdot \mathrm{dia}^{-1} \cdot \mathrm{kPa}^{-1}$, a $25^{\circ} \mathrm{C}$ e gradiente de $75 \%$ UR. Os filmes sem adição de glicerol na formulação (T1, T3 e T7) apresentaram os maiores valores numéricos de coeficiente de permeabilidade ao vapor d'água (19 a $\left.24 \cdot 10^{3} \mathrm{~g} \cdot \mu \mathrm{m} \cdot \mathrm{m}^{-2} \cdot \mathrm{dia}^{-1} \cdot \mathrm{kPa}^{-1}\right)$. Vários autores verificaram este efeito ${ }^{[26,33]}$ e Garcia et al. ${ }^{[26]} \mathrm{o}$ atribui a fissuras e poros no filme sem plastificante. Tais fissuras e poros, entretanto, não foram visualizados nas micrografias.

O aumento da concentração de glicerol de $10 \%$ (T9) para $20 \%$ (T2, T4, T6 e T8) aumentou a permeabilidade ao vapor d'água, devido à elevada afinidade do glicerol pela água, que favorece a solubilização deste permeante no biopolímero. Os plastificantes também conferem flexibilidade maior à estrutura polimérica, aumentando a mobilidade das macromoléculas, facilitando assim a difusão das moléculas de água através do biofilme ${ }^{[32]}$.
Mali et al. ${ }^{[34]}$ relata em seu trabalho que o aumento da concentração do glicerol em filmes de amido de inhame não causou diferença significativa na permeabilidade ao vapor d'água, porém uma tendência ao aumento da permeabilidade de vapor de água foi observada com o aumento da concentração do glicerol. Portanto, o efeito do glicerol na permeabilidade está associado à sua concentração na formulação, visto que afeta a solubilidade do permeante no biopolímero e a formação de espaços vazios na estrutura polimérica, por onde se difunde o permeante. Aumentando-se a solubilidade e a difusibilidade do permeante no polímero, aumenta a permeabilidade. Por outro lado, o plastificante pode minimizar imperfeições na formação dos filmes de amido, reduzindo a permeação.

Filme de amido de ervilha amarela e glicerol (50:20 amido:glicerol), aplicado sobre copo acrílico contendo $10 \mathrm{~mL}$ de água destilada e armazenado em câmara (10\% UR) apresentou coeficiente de permeabilidade ao vapor d'água igual a $66 \cdot 10^{3} \mathrm{~g} \cdot \mu \mathrm{m} \cdot \mathrm{m}^{-2} \cdot \mathrm{dia}^{-1} \cdot \mathrm{kPa}^{-1}$ a $22{ }^{\circ} \mathrm{C}^{[22]}$. Han et al. ${ }^{[4]}$ verificaram que a permeabilidade $\left(25^{\circ} \mathrm{C}\right.$ e $100 \%$ UR) de filmes de amido (3\%) de ervilhas amarelas e glicerol (60:40 amido:glicerol) foi de $186 \cdot 10^{3} \mathrm{~g} \cdot \mu \mathrm{m} \cdot \mathrm{m}^{-2} \cdot \mathrm{dia}^{-1} \cdot \mathrm{kPa}^{-1}$. Ambos os valores muito superiores ao maior valor $\left(24,4 \cdot 10^{3} \mathrm{~g} \cdot \mu \mathrm{m} \cdot \mathrm{m}^{-2} \cdot \mathrm{dia}^{-1} \cdot \mathrm{kPa}^{-1}\right)$ encontrado neste trabalho para a ervilha verde rugosa, o que evidencia uma matriz menos permeável que as de filmes obtidos com amido de ervilhas amarelas.

Os coeficientes de permeabilidade ao oxigênio dos filmes são apresentados na Tabela 3. Embora sem modelo estatístico significativo, pode-se observar que o menor coeficiente de permeabilidade ao oxigênio foi do tratamento T9 (ponto central) de $4 \mathrm{~mL}$ (CNTP) $\mu \mathrm{m} \cdot \mathrm{m}^{-2} \cdot \mathrm{dia}^{-1} \cdot \mathrm{kPa}^{-1}$ a $23{ }^{\circ} \mathrm{C}$ e $75 \%$ UR. Assim, tem-se que o filme correspondente à formulação T9 (4\% amido e $10 \%$ glicerol) apresentou as menores permeabilidades, ou seja, foi o de maior barreira a gases e a umidade, dentre as formulações estudadas. A literatura já indicava a possibilidade de obtenção de filmes de amido de ervilha com boa barreira ao oxigênio em umidades intermediárias, de 45 a 50\% UR, a exemplo dos estudos de Mehyar e $\operatorname{Han}^{[5]}\left(1,4\right.$ mL. $\mu m \cdot m^{-2} \cdot \operatorname{dia}^{-1} \cdot \mathrm{kPa}^{-1}$ a $45 \%$ UR $)$ e de Han et al. ${ }^{[4]}$ (71 a $94 \mathrm{~mL} \cdot \mu \mathrm{m} \cdot \mathrm{m}^{-2} \cdot \mathrm{dia}^{-1} \cdot \mathrm{kPa}^{-1}$ a $50 \%$ UR). Este estudo resultou na obtenção de filmes de amido com boa barreira ao oxigênio, mesmo em alta umidade relativa $(75 \%)$.

O aumento da concentração de glicerol de $10 \%$ (T9) para $20 \%$ (T2, T4, T6 e T8) também aumentou a permeabilidade ao oxigênio, para valores da ordem de 6 a $13 \mathrm{~mL}$ (CNTP) $\mu \mathrm{m} \cdot \mathrm{m}^{-2} \cdot \mathrm{dia}^{-1} \cdot \mathrm{kPa}^{-1} \mathrm{a}$ $23{ }^{\circ} \mathrm{C}$ e $75 \%$ UR, provavelmente devido ao aumento da mobilidade das macromoléculas, facilitando assim a difusão do permeante através do biopolímero ${ }^{[2,27]}$.

\section{Conclusões}

Os biofilmes obtidos a partir de amido de ervilha verde do tipo rugosa, associado ou não à goma xantana e ao glicerol, se comparados com os biofilmes de amido de ervilha amarelas e outras fontes de amido apresentaram melhor barreira ao oxigênio e ao vapor d'água. Se comparado, entretanto, aos polímeros à base de petróleo, a permeabilidade ao oxigênio dos biofilmes estudados é 
baixa, podendo ser equiparável às características das poliamidas (nylon), polímero sintético muito utilizado nas embalagens a vácuo e com atmosfera modificada. Contudo, estes filmes são ainda muito permeáveis ao vapor d'água.

As propriedades dos biofilmes foram afetadas pela composição da solução filmogênica. $\mathrm{O}$ aumento da concentração de amido de ervilha na solução filmogênica implicou no aumento da espessura e da solubilidade em água dos biofilmes. $\mathrm{O}$ aumento da concentração do glicerol aumentou a espessura e a solubilidade e os coeficientes de permeabilidade ao vapor d'água e ao oxigênio.

$\mathrm{O}$ aumento da concentração da goma xantana não interferiu nas propriedades estudadas. Apesar de haver indicações estatísticas acerca da influência da goma na permeabilidade ao oxigênio e ao vapor de água, estudos adicionais, com mais pontos axiais ou teores adicionais deste componente, seriam necessários para ajuste dos modelos polinomiais.

A baixa solubilidade em água é uma indicação de que estes filmes poderão ser utilizados para vários alimentos, o que deverá ser testado em termos de desempenho e de atendimento à legislação vigente.

\section{Agradecimentos}

Os autores agradecem o apoio financeiro ao projeto, concedido pela Fundação de Amparo a Pesquisa do Estado de São Paulo (FAPESP) - Brasil.

\section{Referências Bibliográficas}

1. Texeira, E. M. - "Utilização de amido de mandioca na preparação de novos materiais termoplásticos", Tese de Doutorado, Universidade de São Paulo, Instituto de Química de São Carlos, Brasil (2007).

2. Ratnayake, W. S.; Hoover, R. \& Warkentin, T. - Starch/Stärke, 54, p.217, (2002).

3. Zhang, Y.; Han, J. H. - J. Food Sci., 71, p.109 (2006).

4. Han, J. H.; Seo, G. H.; Park, I. M.; Kim, G. M. \& Lee, D. S. - J. Food Sci., 71, p.290, (2006).

5. Mehyar, G. F. \& Han, J. H. - J. Food Sci., 69, p.449 (2004).

6. Ratnayake, W. S.; Hoover, R. \& Warkentin, T. - Starch/Stärke, 54, p.217 (2002).

7. Liu, Z. \& Eskin, N. A. M. - Food Hydrocoll., 12, p.37 (1998).

8. Rojas, J. A.; Rosell, C. M. \& Barber, C. B. - Food Hydrocoll., 13, p.27 (1999).

9. Munhoz, M. P.; Weber, F. H. \& Chang, Y. K. - Cia. Tec. Alim., 24, p.403 (2004).

10. Chaisawang, M. \& Suphanthakira, M. - Food Hydrocoll., 20, p.641 (2006).

11. Lee, M. H.; Baek, M. H.; Cha, D. S.; Park, H. J. \& Lin, S. T. - Food Hydrocoll., 16, p.345, (2002).
12. Santos, V. P.; Suzuki, M. P.; Cereda, M. P.; Scamparini, A. R. P. - Food Hydrocoll., 19, p.1064 (2005).

13. Lafargue, D.; Lourdin, D. \& Doublier, J. L. - Carbohydr. Polym., 70, p.101 (2007).

14. Mali, S.; Grossman, M. V. E. - J. Agric. Food. Chem., 24, p.7055 (2003).

15. Matta Junior, M. D. "Caracterização de biofilmes obtidos a partir de amido de ervilha (pisum sativum) associado à goma xantana e glicerol”, Dissertação de Mestrado, Universidade de São Paulo, Brasil (2009).

16. Gontard, N.; Duchez, C.; Cuq, J. L. \& Guilbert, S. - Int. J. Food Sci. Technol., 29, p.39 (1994).

17. ASTM - "ASTM E 96/E 96M-05 - Standard test methods for water vapor transmission of materials", Philadelphia (2005).

18. ASTM - "ASTM F 1927-07 - Standard test method for oxygen gas transmission rate through plastic film and sheeting using coulometric sensor", Philadelphia (2007).

19. Themeier, H.; Hollmann, J; Neese, U. \& Lindhauer, M. G. - Carbohydr. Polym., 61, p.72, (2005).

20. Hedley, C. L.; Bogracheva, Y. T. \& Wang, T. L. - Starch/Stärke., 54, p.235 (2002).

21. Zhou, Y.; Hoover, R.; Liu, Q. - Carbohydr. Polym., 57, p. 235 (2004).

22. Zhang, Y. \& Han, J. H. - J. Food Sci., 71, p.253 (2006).

23. Liu, Z. \& Han, J. H. - J. Food Sci., 70, p.31 (2005).

24. Leyva, M. B.; Chávez, P. T.; Wong, B. R.; Jatomea, M. P. \& Bojórquez, F. B. - Starch/Stärke, 60, p.559 (2008).

25. Laohakunji, T. N. \& Noomhorm, A. - Starch/Stärke, 56, p.348 (2002).

26. Garcia, M. A.; Martino, M. N. \& Zaritzky, N. E. - J. Food Sci., 65, p.941 (2000).

27. Wang, J.; Zhengyu, J. \& Xiaoping, Y. - Food Chem., 20, p.101 (2007).

28. Garcia, M. A.; Pinotti, A. \& Zaritzky, N. E. - Starch/Stärke, 58, p.453 (2006).

29. Santos, V. P.; Suzuki, M. P.; Cereda, M. P. \& Scamparini, A. R. P. Food Hydrocoll., 19, p.1064 (2005).

30. Bertuzzi, M. A.; Armada, M. \& Gottifredi, J. C. - J. Food Eng., 17, p.82 (2007).

31. López, O. V.; Garcia, M. A.; Zaritzky, N. E. - Carbohydr. Polym., 73, p.573 (2008).

32. Sarantópoulos, C. I. G. L.; Oliveira, L. M.; Padula, M.; Coltro, L.; Alves, R. M. V. O. \& Garcia, E. E. C. - "Embalagens plásticas flexíveis: principais polímeros e avaliação de propriedades”, Campinas (2002).

33. Talja, R. A.; Helén, H.; Ross, Y. H. \& Jouppila, K. - Carbohydr. Polym., 67, p.288 (2007).

34. Mali, S.; Grossman, M. V. E.; Garcia, M. A.; Mertino, M. N. \& Zaritzky, N. E. - Carbohydr. Polym., 50, p.379 (2002).

Enviado: $14 / 07 / 10$

Aceito: $13 / 08 / 10$

DOI: $10.1590 / \mathrm{S} 0104-14282011005000011$ 